\title{
Analyzing the Role of Communications Technology in C4i Scenarios: A Distributed Cognition Approach
}

Guy H. Walker, ${ }^{1}$ Neville A. Stanton, ${ }^{2}$ Huw Gibson, ${ }^{2}$ Chris Baber, ${ }^{2}$ Mark S. Young, ' and Damian Green'

'Human Factors Integration Defence Technology Centre (HFI DTC), Brunel University, School of Engineering and Design, Uxbridge, UB8 3PH, UK;

${ }^{2}$ University of Birmingham, School of Electronic, Electrical and Computing. Engineering, Edgbaston, Birmingham, B15 2TT, UK.

\section{ABSTRACT}

Command, Control, Communications, Computers, and Intelligence (C4i) is defined as the management infrastructure required for coordination and planning in situations in which multiple individuals, often dispersed geographically, have to achieve a common goal (Harris \& White, 1987). C4i is an example of a joint cognitive system where intelligent processes transcend the boundaries of the individual actor (Rogers, 1997, 1), and information is dispersed among human and non-human agents in the wider context. A methodology is proposed that is based on the integration of five individual methods. This approach enables information that individuals use for decision making in $\mathrm{C} 4 \mathrm{i}$ to be captured and represented as a form of knowledge network. This network provides a powerful representation of Situational A wareness, or 'who knows what'. Knowledge that is shared between agents in the scenario can be identified, which in turn, enables an assessment of the knowledge that has to be communicated between agents and how it is and could be mediated by technology. The method is applied to a live scenario drawn from the United Kingdom (U.K.) railway industry, for which the level of critique available for the assessment of technology within these intelligent systems is significantly enhanced.

Reprint requests to: Guy H. Walker, e-mail: guy.walker@brunel.ac.uk 


\section{KEYWORDS}

real time systems, situation awareness, knowledge network, user centered design

\section{INTRODUCTION}

\section{Background}

The acronym C4i stands for Command, Control, Communications, Computers, and Intelligence, a generic term that refers to the management infrastructure for any large, complex, and dynamic resource system (Harris \& White, 1987). Some form of underlying mechanism for organization and planning is needed in virtually any instance having multiple individuals, or teams of individuals, often separated geographically, who must communicate and coordinate to achieve an efficient outcome to a common goal. Different types of information technology are (or can be) used within $\mathrm{C4i}$ with the aim of supporting or facilitating communication and coordination. The selection and design of any such technology occurs within a wider context of numerous challenges identified by Harris and White. Foremost amongst these are the following:

1. there is currently no theory of command and control,

2. there is informational chaos, and

3. there is an ongoing technology revolution.

To specify technology requirements within such a context is difficult. The purpose of this article is (a) to offer a number of novel perspectives on, and methods for, the systematic analysis of any $\mathrm{C} 4 \mathrm{i}$ scenario and (b), how technology could or should be applied within them.

\section{C4 'i' for Intelligence}

The suffix ' $i$ ' of $\mathrm{C} 4 \mathrm{i}$ betrays its militaristic origins and reflects the kind of intelligence that commanders receive from the battle-field. Nevertheless, advancing the case for $\mathrm{C} 4 \mathrm{i}$ being a form of intelligent system on a number of 
levels is easy. At the outset, $\mathrm{C} 4 \mathrm{i}$ is a purposeful intelligently adaptive endeavor representing progress toward a defined outcome. This progress occurs according to time. As such, $\mathrm{C} 4 \mathrm{i}$ can be regarded as a form of real-time system, in which a response to externally generated input events is required within a finite and specified period (Young, 1982). C4i is also a powerful example of distributed cognition. C4i amply demonstrates how "intelligent processes in human activity transcend the boundaries of the individual actor" (Rogers, 1997, 1) and illustrates the idea of a joint cognitive system of collaborative human and non-human agents (Hollnagel, 1993). The idea of a joint cognitive system is, therefore, very similar to that of a distributed system, perhaps increasingly so in cases where non-human agents in $\mathrm{C4} \mathrm{i}$ scenarios are advanced forms of information technology with sometimes real, as opposed to abstract analogues to human intelligence. An illustration of this can be drawn out of a recent analysis of C4i in Air Traffic Control (Walker et al., 2005) which reveals the prominence of on-board Flight Management Systems (FMS). This system is the aircraft's 'autopilot' that relieves the pilot of large sections of operational control. These are also systems that can be argued as being, like the pilot and air traffic controller, situationally aware of where they are (e.g. navigation and positioning systems), who they are (e.g. what pre-defined identifier has been attributed which allows it to participate in the air traffic management system), and what they are doing (e.g. the aircraft can automatically respond to system disturbances by correcting and anticipating the required movement of control surfaces to remain in balanced flight). It could even be argued that these systems have some form of selfawareness, through multiple redundancy and duplication of monitoring systems that check each other and work on a 'majority voting' basis. Regardless of how far this argument is taken, insofar as human and nonhuman agents in a scenario are concerned, they can both be regarded in terms of what information is flowing around the system, how it is processed, what outputs are derived and how they are represented.

\section{Insights from Within Live C4i}

Researchers from the Human Factors Integration Defence Technology Centre (HFI DTC) consortium have under-taken several large-scale analyses 
of $\mathrm{C} 4 \mathrm{i}$ scenarios in a number of civil and military domains. This includes the air traffic control scenario mentioned above, a naval training simulator, the emergency services, and maintenance activities in the UK's electricity transmission network and railway network. Regardless of domain, key issues arising from these analy ses are that:

1. a significant portion of complexity in $\mathrm{C} 4 \mathrm{i}$ scenarios derives from a requirement on the personnel involved to time and precisely sequence their actions,

2. pursuant to the latter, each communication has a routine requirement to identify the agent involved and the purpose of the communication, due to the predominantly verbal nature of the communications technology in use. Also,

3. communication plays a major part in and is dependent on situational awareness, and

4. key agents are required to develop situational awareness about current and future requirements communicated by various parties with various perspectives on the scenario. Geographically remote 'commanders' or key decision makers then have to integrate operational concerns with wider contextual and strategic issues.

The role of communication and the concept of Situation Awareness (SA) emerge as key themes that define how technology could or should be applied within C4i. Moray $(2004,4)$ defines SA not as a particular psychological function but simply as the ability to "keep track of what is going on around you in a complex and dynamic environment." Situation Awareness offers an explanation for how key agents (or any agent) engaged in decision making activity within $\mathrm{C} 4 \mathrm{i}$ scenarios use systems and technology to combine longerterm strategic goals with shorter-term operational goals in real time (Sukthankar, 1997). Agents are required to keep track of a number of critical variables in a dynamic and changeable environment and must be able to predict how these variables will change in the near future so that the system can be adapted to new requirements (Gugerty, 1998). The greater the decision making load is on an individual agent, the more that this will tend to be the case.

Smith and Hancock (1995) suggest a degree of theoretical tension between the definition of SA as a process or a product. Whichever perspective 


\section{TABLE 1}

Distributed SA in an emergency services fire fighting C4i scenario

\begin{tabular}{|l|l|l|l|}
\hline Agent & PERCEPTION & COMPREHENSION & PROJECTION \\
\hline Gas analyzer & $\begin{array}{l}\text { Senses level of } \\
\text { toxic gas }\end{array}$ & $\begin{array}{l}\text { Calculates current gas } \\
\text { level and compares } \\
\text { against threshold }\end{array}$ & $\begin{array}{l}\text { Indicates that gas level } \\
\text { could be hazardous to } \\
\text { health if exposure } \\
\text { prolonged }\end{array}$ \\
\hline Firefighter\#1 & $\begin{array}{l}\text { Reads level on } \\
\text { meter }\end{array}$ & $\begin{array}{l}\text { Determines high level } \\
\text { equates to risk to self }\end{array}$ & Need to exit building \\
\hline $\begin{array}{l}\text { Incident } \\
\text { Commander }\end{array}$ & $\begin{array}{l}\text { Sees fire-fighter } \\
\text { pause in doorway }\end{array}$ & $\begin{array}{l}\text { Decides gas level } \\
\text { presents risk to crew }\end{array}$ & $\begin{array}{l}\text { Switch to defensive } \\
\text { response }\end{array}$ \\
\hline
\end{tabular}

is taken, a relatively invariant property of SA is that it generates knowledge. At the most basic level, SA is "eventually reducible to some form of...information in working memory" (Bell \& Lyon, 2000, 42). Such information supports effective decision making. Smith and Hancock (1995) further argue that SA embodies a close coupling between the agent and the environment in which knowledge is distributed and represented across both. The common denominator within this notion of distributed cognition, for both humans and technical artifacts, is that of 'representational states'. This can be clarified by a recent $\mathrm{C} 4 \mathrm{i}$ example drawn from the fire service shown in Table 1 (Baber et al., 2004). In the particular scenario in question, a handheld gas analyzer was used to determine whether fumes from a chemical incident were at risky levels. Once a threshold had been exceeded, the fire-fighter carrying the device decided to evacuate the area. The Incident Commander, watching the fire-fighter, realized the risk and ordered the crew to return to their vehicles. This apparently simple chain of events involving human (firefighters) and non-human agents (the gas analyzer) illustrates how 'representations' (e.g. indicate hazardous gas level) interact with processes (e.g. need to exit building).

This example illustrates two key factors. First, the 'knowledge' that comprises $\mathrm{SA}$ is distributed across the system in the manner described above. 
Second, in a departure from much of current research on team SA (e.g. Salas et al., 1995) there is often implicit communication of information (e.g., where the incident commander merely sees the fire-fighter pause in the doorway) rather than detailed exchange of information, perhaps verbally. Furthermore, as the example above hints, it is neither necessary nor desirable for all agents to possess identical SA because different tasks and perspectives require different SA. The key factor is that technological artefacts within C4i scenarios have to be specified in a manner to ensure that SA is behaviorally interacting and compatible, as in the example above.

\section{Summary}

Returning to the main topic of this paper, the following key issues need to be considered.

1. C4i is dominated by the creation and maintenance of SA in order to support effective decision-making and, therefore, to meet operational objectives.

2. The knowledge underpinning $\mathrm{SA}$ is distributed across an intelligent system comprised of human and non-human agents.

3. The means by which knowledge passes between agents can be verbal or non verbal, explicit or implicit.

4. The knowledge requirements of each agent are necessarily different according to their role and associated goals within the scenario.

In summary, this paper presents a methodology for representing SA in C4i scenarios as a distributed phenomenon, attributing knowledge to specific agents, and using this perspective to provide a means to improve and systematically critique the application of information technology.

\section{METHODOLOGY}

\section{Data Collection Methods}

The first step in the analysis of $\mathrm{C} 4 \mathrm{i}$ scenarios is to extract data from them in a meaningful way. Annett (2004) argues that data collection should comprise 
observation and interviews at the very least. Both Annett and Kieras (2004) argue for the least intrusive method of observation that circumstances permit, therefore, a two-step process of observation and interview is proposed. Observation takes the form of multi-site activity sampling (Stanton et al., 2005). Activity sampling is an aid to unobtrusively recording activity (or actual behavior) in the field.

Although observational techniques provide information on the observable inputs and outputs of human information processing, they produce limited data on the process of decision-making. The study of decision-making in realworld situations has received a good deal of attention and a growing emphasis is being placed on the use of interviews to collect such information, particularly if the interviewees are describing a recent event and how they dealt with it. The Critical Decision Method (CDM; Klein \& Armstrong, 2005 ) is a contemporary example. According to Klein, "The CDM is a retrospective interview strategy that applies a set of cognitive probes to actual non-routine incidents that required expert judgment or decision making." (Klein et al., 1989, 464). Table 2 presents the CDM probes devised by O'Hare et al. (2000) that are re-used in the current analysis.

\section{Task and Goal Modeling}

Hierarchical Task Analysis (HTA) is a way of analyzing complex tasks (Annett, 2005). In appearance, an HTA is similar to some of the flow diagrams and other systems analytical techniques like UML but instead of describing processes and/or artefacts, HTA describes goals and the hierarchical decomposition of them. The sequence of actions, precursors and external conditions pursuant of goals are represented in HTA as plans. An HTA, therefore, models a scenario with a nested hierarchy of goals, operations and plans that specify the how, when, and under what conditions goals and operations become active and must be performed and met. The advantage of HTA is that it is inherently flexible; the approach can be used to describe any intelligent system, even C4i. In its application here, the definition of HTA proceeds with reference both to what has been observed and what may have been previously defined through any pre-existing task analyses. 
TABLE 2

CDM Probes (O'Hare, et al., 2000)

\begin{tabular}{|c|c|}
\hline Cognitive Cue & Sample Question \\
\hline Goal specification & What were your specific goals at the various decision points? \\
\hline Goal identification & $\begin{array}{l}\text { What features were you looking at when your formulated your decision? } \\
\text { How did you know that you needed to make the decision? } \\
\text { How did you know when to make the decision? }\end{array}$ \\
\hline Expectancy & $\begin{array}{l}\text { Were you expecting to make this type of decision during the course of the } \\
\text { event? } \\
\text { Describe how this affected your decision-making process. }\end{array}$ \\
\hline Conceptual model & $\begin{array}{l}\text { Are there situations in which your decision would have tumed out } \\
\text { differently? } \\
\text { Describe the nature of these situations and the characteristics that would } \\
\text { have changed the outcome of your decision. }\end{array}$ \\
\hline Influence of uncertainty & $\begin{array}{l}\text { At any stage, were you uncertain about either the reliability or the } \\
\text { relevance of information that you had available? } \\
\text { At any stage, were you uncertain about the appropriateness of the } \\
\text { decision? }\end{array}$ \\
\hline Information integration & $\begin{array}{l}\text { What was the most important piece of information that you used to } \\
\text { formulate the decision? }\end{array}$ \\
\hline Situation awareness & $\begin{array}{l}\text { What information did you have available to you when formulating the } \\
\text { decision? }\end{array}$ \\
\hline Situation assessment & $\begin{array}{l}\text { Did you use all the information available to you when formulating the } \\
\text { decision? } \\
\text { Was there any additional information that you might have used to assist in } \\
\text { the formulation the decision? }\end{array}$ \\
\hline Options & $\begin{array}{l}\text { Were there any other altematives available to you other than the decision } \\
\text { that you made? } \\
\text { Why were these altematives considered inappropriate? }\end{array}$ \\
\hline Decision blocking & $\begin{array}{l}\text { Was there any stage during the decision making process in which you } \\
\text { found it difficult to process and integrate the information available? } \\
\text { Describe precisely the nature of the situation. }\end{array}$ \\
\hline Basis of choice & $\begin{array}{l}\text { Do you think that you could develop a rule, based on your experience, } \\
\text { which could assist another person to make the same decision } \\
\text { successtully? } \\
\text { Do you think that anyone else would be able to use this rule successfully? } \\
\text { WhyMhy not? }\end{array}$ \\
\hline Generalization & $\begin{array}{l}\text { Were you at any time reminded of previous experiences in which a similar } \\
\text { decision was made? } \\
\text { Were you at any time reminded of previous experiences in which a } \\
\text { different decision was made? }\end{array}$ \\
\hline
\end{tabular}


It is possible to integrate meaningfully these information sources on goal structure to produce a task analysis that accurately describes what has been observed, is consistent with what has already been pre-defined, and covers key decision points elaborated in the Critical Decision Interview.

\section{Propositional Network}

Knowledge and SA have been identified as key concepts within C4i. There are several ways of representing knowledge (and therefore SA), including networks. The idea that 'knowledge' can be represented in the form of a network has been a major source of discussion of memory in cognitive psychology since the 1970s. Initially, researchers used Semantic Networks as a way of representing the association between items within a concept. Such an approach gave rise to theoretical insights like spreading activation (Quillian, 1969; Collins \& Loftus, 1975). The basic premise is that an item of knowledge will be easier to process if it has a high level of activation. According to Collins and Loftus (p. 408), other nodes linked to this active node also become activated, namely, "The spread of activation constantly expands, first to all the nodes linked to the first node, then to all the nodes linked to each of these nodes, and so on."

Propositional Networks are like semantic networks in that they contain nodes with words and relations between nodes. It is argued that the application of basic propositions and operators enables dictionary-like definitions of concepts to be derived (Ogden, 1987). Stanton et al. (submitted) take this basic notion and extends it to offer a novel way of modeling knowledge and SA in any scenario. From an overall 'systems perspective' SA within a $\mathrm{C} 4 \mathrm{i}$ scenario, and indeed individual $\mathrm{SA}$, can be understood as activated knowledge (Bell \& Lyon, 2000). Knowledge objects are analogous to propositions and can be defined as "an entity or phenomenon about which an individual requires information in order to act effectively" (C. Baber, personal communication, 2004). Stanton et al. put forward the notion that propositional networks offer a novel and effective means of representing knowledge, its distribution and activation amongst actors, and across time. In so doing, this offers a logical representation of the knowledge comprising SA at the level of the whole system, sub-system, teams, groups, or individuals; in 
other words, Stanton et al. propound a theory of Distributed Situation Awareness. The approach has several compelling advantages:

1. First, the network shows the totality of knowledge used in the scenario, at a systems level, regardless of whether agents in the scenario are human or technical.

2. Second, shared SA can be accessed from the critical decision interview, in which agents can be attributed to knowledge objects within the network.

3. Third, a real time system like C4i occurs within a "volume of time and space" (Endsley, 1995, 36). Illustrating this key temporal aspect of SA is made possible by animating the propositional network in terms of task phases and active and non-active knowledge objects thereof.

4. Fourth, a major advantage of propositional networks is that they do not differentiate between different types of knowledge object or node (e.g. knowledge related to objects, people, or ideas). From a design perspective, therefore, they do not constrain assessments to consideration of existing configurations of people and objects, rather to the required knowledge elements associated with a scenario. This is a key point.

An opportunity arises within this paper to apply the Distributed Situational Awareness approach in a real sense to $\mathrm{C} 4 \mathrm{i}$ scenarios.

\section{Communications Usage Diagram}

The Communications Usage Diagram (CUD) (Watts \& Monk, 2000) is the means by which the Distributed Situation Awareness approach can be translated and structured in order to inform the design and implementation of technology within C4i. The CUD is a systematic technique used to help describe collaborative activity between distributed teams. It uses the output of the observations, Hierarchical Task Analysis, Critical Decision Method and Propositional Network to describe in tabular format how, why, and when communications between agents occur, the technology used, and the advantages and disadvantages associated with it (for an example see Table 3).

Two important additions to the method have been developed. When knowledge objects in the Propositional Network become jointly activated by 
TABLE 3

Section of enhanced CUD table for a railway maintenance scenario (setting up a track possession)

\begin{tabular}{|c|c|c|c|c|c|}
\hline \multicolumn{2}{|c|}{ LOCATION } & \multirow[b]{2}{*}{$\begin{array}{l}\text { Comms } \\
\text { Media }\end{array}$} & \multirow[b]{2}{*}{$\begin{array}{l}\text { Knowledge } \\
\text { objects }\end{array}$} & \multirow[b]{2}{*}{$\begin{array}{l}\text { Effects of } \\
\text { Comms Media } \\
\text { used }\end{array}$} & \multirow[b]{2}{*}{$\begin{array}{l}\text { Recommended } \\
\text { Comms resource }\end{array}$} \\
\hline $\begin{array}{l}\text { Work } \\
\text { site }\end{array}$ & $\begin{array}{l}\text { Signal } \\
\text { box }\end{array}$ & & & & \\
\hline & & $\begin{array}{l}\text { Signal Post } \\
\text { Telephone }\end{array}$ & $\begin{array}{l}\text { Time } \\
\text { Possession } \\
\text { Call } \\
\text { Signaler } \\
\text { WON } \\
\text { Information } \\
\text { Network } \\
\text { Trains }\end{array}$ & $\begin{array}{l}\quad+ \\
\text { Sound stable. } \\
\text { Increased } \\
\text { likelihood of } \\
\text { talking to } \\
\text { correct } \\
\text { signaler. } \\
\quad- \\
\text { Not hands free } \\
\text { but hands may } \\
\text { be required to } \\
\text { complete } \\
\text { paperwork. } \\
\text { Affected by } \\
\text { environmental } \\
\text { conditions as } \\
\text { located } \\
\text { outside. }\end{array}$ & $\begin{array}{l}\text { Face-to-face } \\
\text { comms. } \\
\text { Written } \\
\text { information } \\
\text { Shared } \\
\text { situational } \\
\text { display }\end{array}$ \\
\hline & & $\begin{array}{l}\text { See } \\
\text { 'technology } \\
\text { in use' }\end{array}$ & $\begin{array}{l}\text { See } \\
\text { 'distributed } \\
\text { SA' }\end{array}$ & $\begin{array}{l}\text { See } \\
\text { 'advantages } \\
\text { and } \\
\text { disadvantages' }\end{array}$ & See 'critique' \\
\hline
\end{tabular}

different agents, a real indication of shared knowledge is gained. Where knowledge is shared, the analyst needs to assess the level and type of communication and the means by which it could or should be facilitated. This assessment can now proceed in a highly structured manner according to an analysis of knowledge and SA (central concepts within $\mathrm{C4i}$ ). As such, the impact of this analysis is increased, enabling a significant advance in the level of critique available from the Communications Usage Diagram method. 


\section{Assessing the Role of Communication Technology in C4i Systems}

The integration of all the above methods enables a structured and systematic critique of an existing $\mathrm{C} 4 \mathrm{i}$ scenario and fits well within an iterative design process of refinement and re-analysis. Clearly, such an approach is constrained by the existil stem. Thus, the propositional network will represent the current systen. ad the knowledge objects that require sharing, even if this system is suboptimal. In cases where a system is being analyzed before being built (an analytical prototyping perspective), it is possible to take a higher level view by considering the overall goal structure of the HTA and to consider what knowledge objects need, 'in theory', to be active, and where they should be distributed and shared. Viewing the higher structural elements of the HTA progressively releases the analyst from the constraints of existing operations and specific tasks, to consider instead the requirements of more general goals. The higher this level of analysis proceeds, however, the more theoretical becomes the exercise of defining the relevant knowledge objects. With these trade-offs in mind, it is possible to adopt interchangeable levels of analysis dependent on the design stage. Even as a strictly theoretical exercise the method remains structured, systematic, scaleable, dynamic, and focused on the mediation of required knowledge.

\section{APPLICATION TO REAL DATA}

\section{Live C4i Scenario}

An example of a complex and dynamic resource system is the maintenance activities undertaken within the U.K. rail industry. Railways were in fact one of the first domains to introduce early forms of 'telegraph' and, therefore, have been carrying out the technologically mediated remote coordination of activities for more than a century (Rolt, 1955). For the purposes of this paper, the scenario merely serves as a source of real data to demonstrate the capability and application of the method.

Broadly speaking, the $\mathrm{C} 4 \mathrm{i}$ activities under consideration are those involved in the setting up of safety systems required when carrying out maintenance of track. A practical illustration of these activities is presented in Fig. 1. 

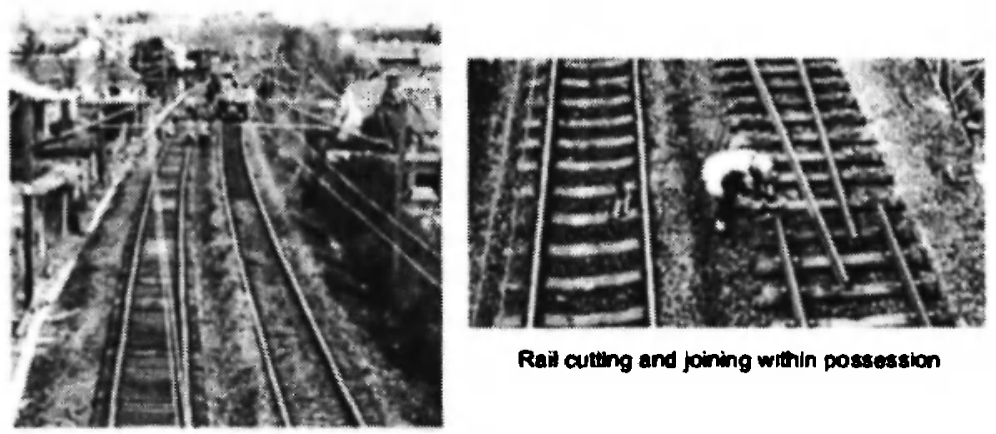

Rail cutting and foining within possession

Pereonnet and on-track machinery laying replacomonl Irack whin a possesston

Fig. 1: Illustration of railway maintenance activities

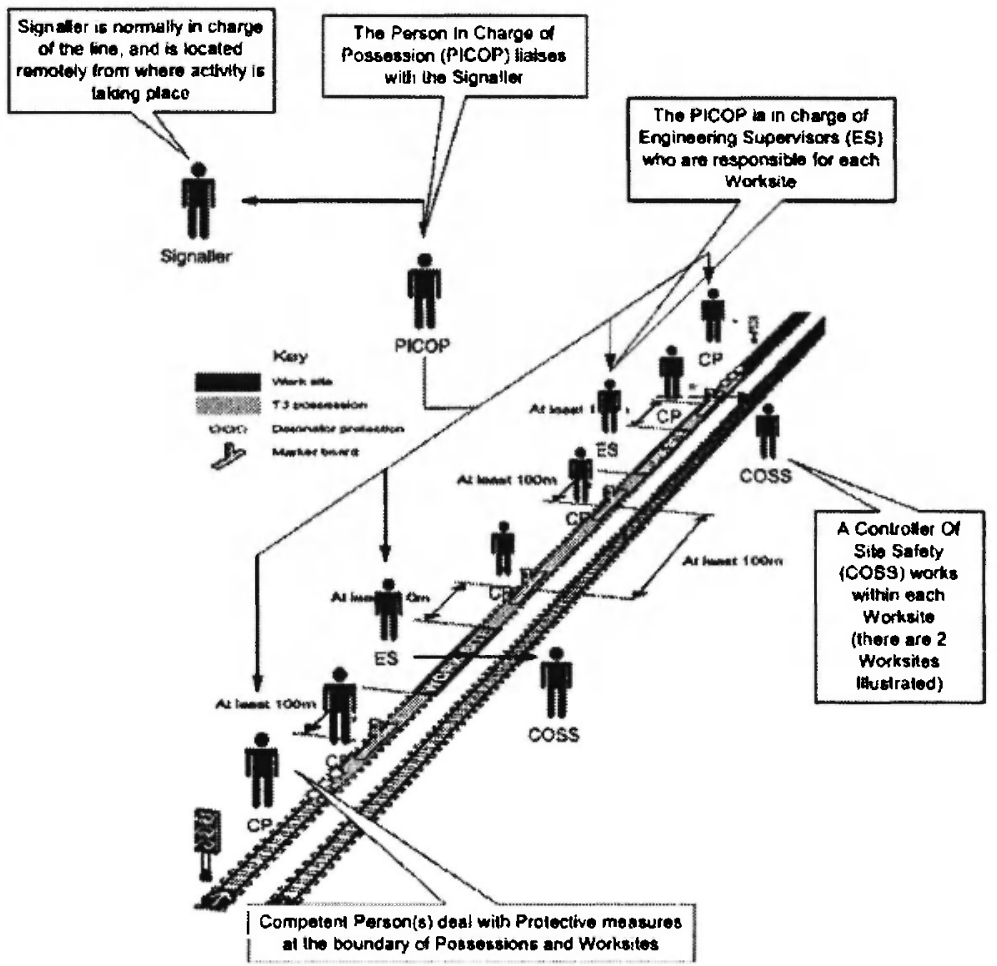

Fig. 2: Illustration of the possession scenario showing dispersion of the personnel involved in setting up two worksites within the possession (adapted from RSSB, 2003.) 
Safety systems are required so that workers on the track do not come into conflict with moving trains, and that trains do not travel over railway infrastructure that is rendered unsafe by the maintenance work, or the requirement for it. Strict procedures underpinning these systems are specified nationally in the U.K. railway industry Rule Book (RSSB, 2003). The key issues are (a) a 'management infrastructure' is required and in place, and (b) these activities on the railway possess all the essential ingredients of $\mathrm{C} 4 \mathrm{i}$ including

- a common goal,

- individuals and teams coordinating to reach it, but

- dispersed geographically, and there are

- numerous systems, procedures and technology to support their endeavor.

The particular scenario describes the processes and activities for setting up an engineering possession for a stretch of track so that planned maintenance can take place (Fig. 2). When an engineering possession takes place, a stretch of railway line leaves the responsibility of the Signaler and transfers to a Person In Charge Of Possession (PICOP). This activity requires coordination among multiple parties. It includes communication between the Signaler and the PICOP (so that appropriate protecting signals are set to danger), and the provision of instructions to a Competent Person (CP) (to place a form of train protection physically on the track at the limits of the possession). Additional complexity comes in the form of a number of individual engineering Worksites within the possession, each of which has an Engineering Supervisor (ES) and Controller Of Site Safety (COSS), who are responsible for setting up and managing each one. The ES will also use CPs to place marker boards as a form of additional protection at the ends of the individual Worksites.

\section{RESULTS OF APPLICATION TO REAL DATA}

\section{Task Networks}

The first step in the methodology, subsequent to collecting data, is to model the goal structure of the scenario using Hierarchical Task Analysis. 


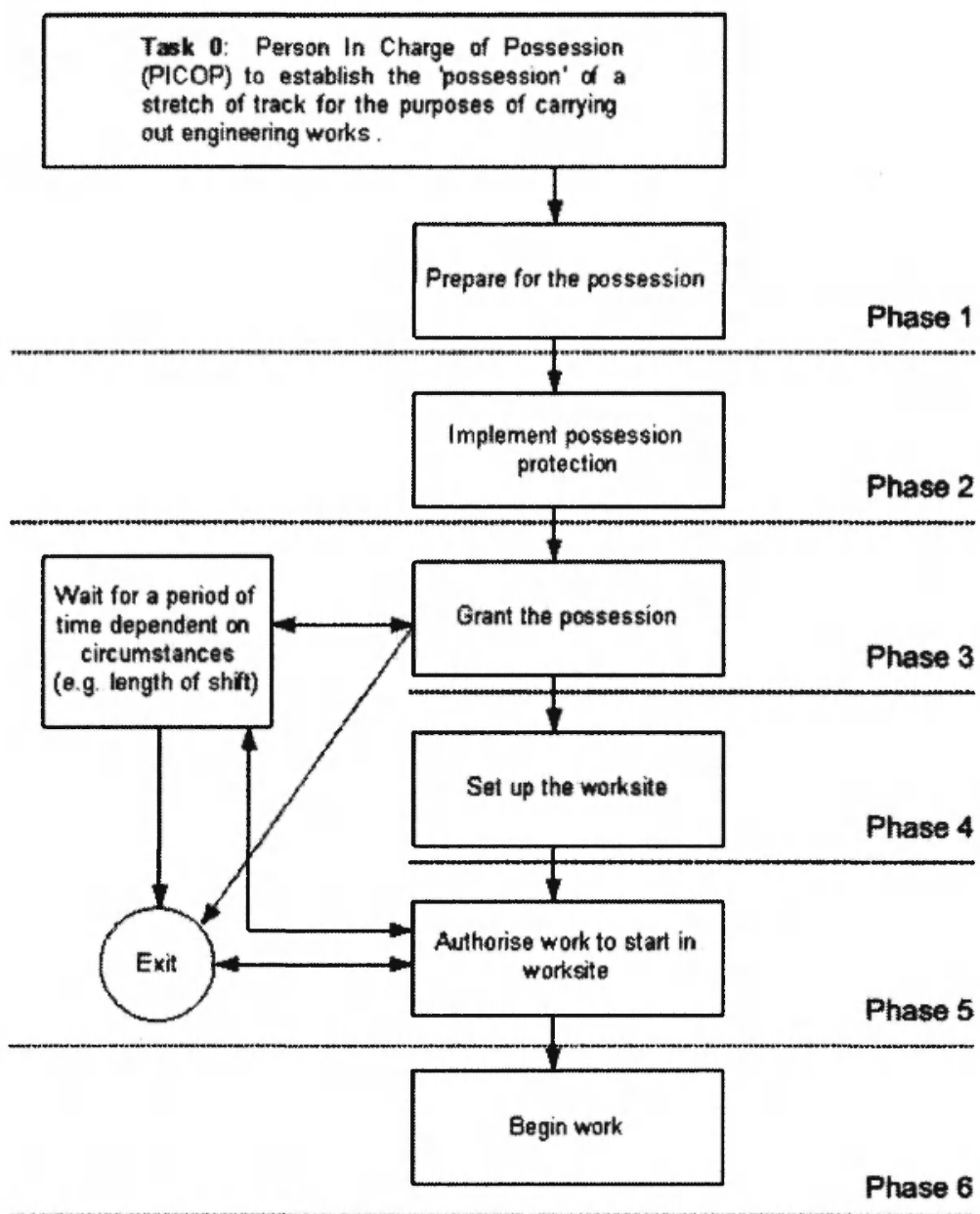

Fig. 3: Task network for planned maintenance scenario

The output of this step can be represented as a task network showing how tasks relate to each other functionally and temporally. In the present case, the highly proceduralized and rigid nature of the activity is seen as a more or less linear task flow (Fig. 3). The Hierarchical Task Analysis (and associated task network) divides the scenarin into functional and temporal phases, each of which can be subject to the Critical Decision Method involving the agent(s) relevant to each phase. 


\section{Critical Decision Method}

The next step is to run through the Critical Decision Method (CDM) procedure and associated cognitive probes (see Table 2). An example of the CDM output table is shown below in Table 4. To convert the Critical Decision Method tables into propositions, a Content Analysis is performed. In the first

\section{TABLE 4}

CDM Output Table for Task Phase One: Prepare for Possession (PICOP and Signaler)

\begin{tabular}{|c|c|c|}
\hline CDM heading & Signaler & PICOP \\
\hline $\begin{array}{l}\text { Goal } \\
\text { specification }\end{array}$ & $\begin{array}{l}\text { Identify need for } \\
\text { <possession> and if and } \\
\text { when they can < grant }>\text { the } \\
\text { possession }\end{array}$ & $\begin{array}{l}\text { To ensure that they can take the } \\
\text { <possession> and when }\end{array}$ \\
\hline $\begin{array}{l}\text { Cue } \\
\text { identification }\end{array}$ & $\begin{array}{l}\text { Telephone <call }>\text { from } \\
<\text { PICOP }>\end{array}$ & $\begin{array}{l}<\text { Weekly operating } \\
\text { notice/briefing }>\end{array}$ \\
\hline Expectancy & $\begin{array}{l}\text { Have <weekly operating } \\
\text { notice }>\text { and done some } \\
\text { preparation. }\end{array}$ & $\begin{array}{l}\text { Have <weekly operating notice> } \\
\text { and done some <preparation>. }\end{array}$ \\
\hline $\begin{array}{l}\text { Conceptual } \\
\text { model }\end{array}$ & $\begin{array}{l}<\text { Traffic }><\text { disturbances }> \\
\text { and }\langle\text { train }><\text { delays }>\end{array}$ & $\begin{array}{l}\text { Lack of < availability }>\text { of } \\
<\text { personne }>\text { to carry out }<\text { other } \\
\text { roles }>\text {, <equipment }>\text { or }<\text { trains }>\end{array}$ \\
\hline Uncertainty & $\begin{array}{l}<\text { Time }>\text { of }<\text { last train }> \\
\text { Is the PICOP the } \\
<\text { PICOP }><\text { named }>\text { on } \\
<\text { documentation }>\end{array}$ & $\begin{array}{l}<\text { Time }>\text { that }<\text { possession }>\text { can be } \\
\text { taken }\end{array}$ \\
\hline Information & $\begin{array}{l}<\text { Availability }>\text { of the } \\
<\text { network }>\text { for the } \\
\text { possession }\end{array}$ & Dependant on $<$ Signaler $>$ \\
\hline $\begin{array}{l}\text { Situation } \\
\text { awareness }\end{array}$ & $\begin{array}{l}<\text { Weekly operating notice }> \\
<\text { Signaler displays }> \\
<\text { Other Signalers }> \\
<\text { Train }>\text { schedule }> \\
<\text { PICOP }><\text { information }>\end{array}$ & $\begin{array}{l}<\text { Weekly operating notice }>\text { and } \\
\text { other }<\text { planning information }> \\
<\text { Communication from Signaler }>\end{array}$ \\
\hline $\begin{array}{l}\text { Situation } \\
\text { assessment }\end{array}$ & $\begin{array}{l}\text { Ask PICOP if a <train> } \\
\text { has just <passed }>\end{array}$ & $\begin{array}{l}\text { Possibly see }<\text { trains }><\text { moving }> \\
\text { on the }<\text { network }>\end{array}$ \\
\hline Options & $\begin{array}{l}\text { To not <grant }>\text { the } \\
\text { <possession }>\end{array}$ & \\
\hline Stress & Some বime pressure > & Some $<$ time pressure $>$ \\
\hline
\end{tabular}


stage, this simply means separating all content words from any function words. For example, the entry in Table 1 "possibly see trains moving on the network" would be reduced to the following propositions <trains $>$, <moving $>$ and $<$ network $>$. Working through the tables leads to a set of Knowledge Objects for each phase. These are checked to ensure that duplication is minimized and then used to construct the propositional network itself. In addition, the Hierarchical Task Analysis can be used to extract Knowledge Objects that may have been omitted in the Critical Decision Method transcripts, or relied upon more heavily if the analysis is proceeding at an analytical rather than functional level.

\section{Knowledge Mapping}

The next stage is to represent the relations between the extracted Knowledge Objects, and their activation, using Propositional Networks. Propositional Networks differ from semantic networks in two ways. First, the words are not necessarily randomly added to the network but involve the definition of propositions. A proposition is a basic statement, i.e., "...the smallest unit about which it makes sense to make the judgment true or false" (Anderson, 1980, 102). Second, the links between words are labeled to define the relationship between propositions. These relations might be in terms of subject and object (in grammatical terms), with a corresponding relation term, e.g., the sentence 'see trains moving' has a subject (movement), an object (trains) and a relation (is) and can be represented as shown in Fig. 4.

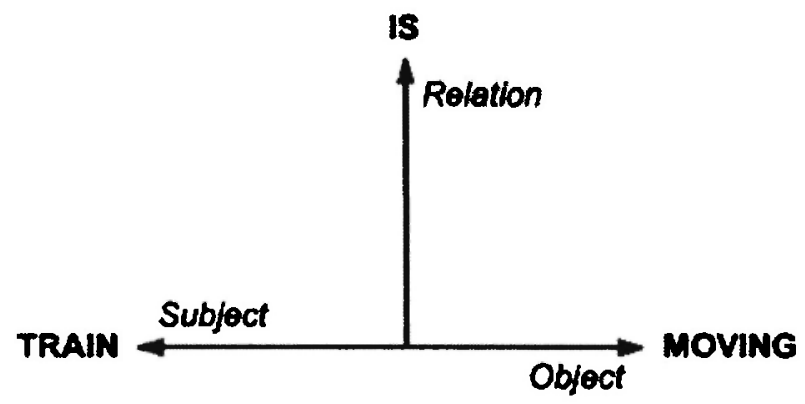

Fig. 4: Construction of a proposition. 
Based on such descriptions, it is possible to claim that one can produce dictionary-like definitions of concepts (and in this case Situational Awareness) through the application of basic propositions and operators (Ogden, 1987). The justification for using a propositional network in this manner is that it represents the 'ideal' collection of knowledge for an incident. As the incident unfolds, so participants will have access to more of this knowledge either through communication with other agents or through recognizing changes in the incident status. An advantage of producing a Propositional Network is that through the use of color-coding/shading it is possible to indicate in a simple visual manner the relation between specific agents and specific objects over the course of an incident, as shown in Fig. 5.

\section{Distributed SA}

The Propositional Network shown in Fig. 5 represents the collection of knowledge underpinning SA at the level of the entire system and for two

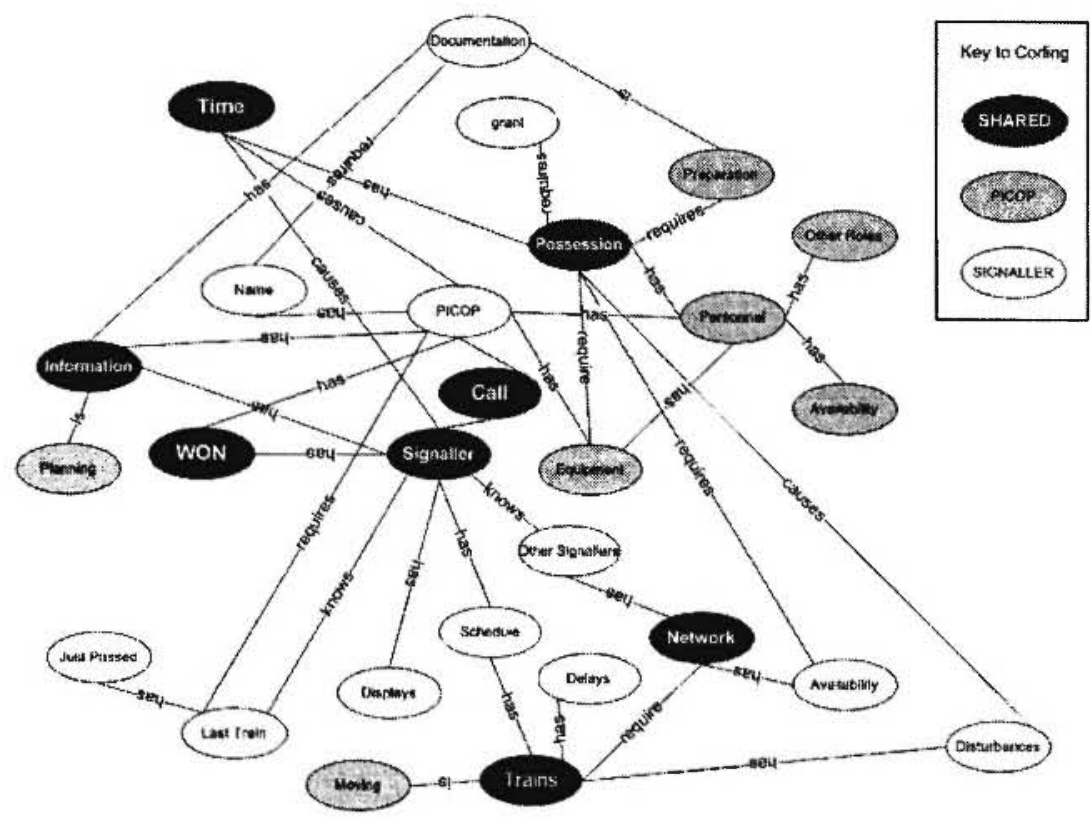

Fig. 5: Propositional Network showing total knowledge objects, those used by individual parties, and those shared between multiple parties 
selected agents in the railway maintenance scenario. It illustrates what needs to be known by whom (distributed Situation Awareness) and when it is required to be known (dynamic Situation Awareness).

As the incident unfolds, so different Knowledge Objects in the network become active. The possession scenario begins with the PICOP and Signaler preparing for the possession. This causes the Knowledge Objects relating to <possession>, <weekly operating notice> and <signaler displays> (among others) to become active. As the scenario progresses to the phase where detonator protection is being prepared for, Knowledge Objects relating to the CP become active e.g. <detonators>. As the situation changes, so the activation of Knowledge Objects alters. Crucially, where there are jointly active nodes, it is necessary to ensure some level of communication between agents.

\section{RESULTS-CRITIQUE OF COMMUNICATIONS TECHNOLOGY}

\section{Technology in Use}

In the current scenario, the technology in use comprises off-the-shelf mobile phones, a signal post telephone (SPT) and a signaler desk telephone. The signal post telephone derives from a basic requirement that a train driver held by a signal at danger for longer than 3 minutes must inform the signaler (RSSB, 2003). The actual telephone equipment is located on a signal at the trackside, usually in a small weatherproof cabinet (Fig. 6). Signals (and associated telephones) are located at regular intervals along the entire length of track. In-cab-radio systems have, to some extent, supplanted the need for train drivers to use these provisions but remain an essential part of operational and maintenance activities. The telephone network on the railways is a highly distributed facility, whereby the signal in question (and associated telephone) may be controlled by a centralized facility possibly $\mathbf{3 0}$ or more miles away. Some form of switchboard facility is usually employed to integrate multiple lines into one desk telephone handset. How this integration is performed varies from legacy systems, such as 'concentrators', to touch-screen interfaces much akin to Air Traffic Management (ATM) systems. In all cases, the SPT is a direct line to the signaler who controls the signal in question, whether they control 5 signals or 50 . 


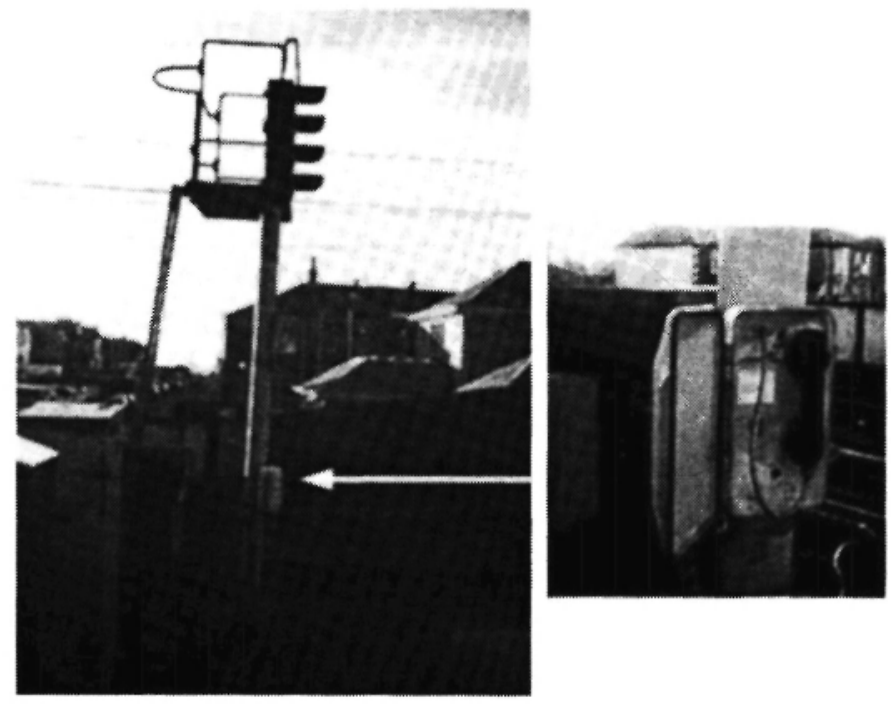

Fig. 6: Signal-Post Telephone (SPT)

\section{Advantages and Disadvantages of Existing Communication Media}

The next stage in the analysis is to consider systematically the advantages and disadvantages of existing technology. This analysis is presented in Table 5.

\section{Design Insights Based on Knowledge Objects}

The next stage of analysis is to integrate the consideration of advantages/ disadvantages with information on shared Knowledge Objects, to provide a detailed critique based on the level and type of communication and its mediation. The critique enables consideration to whether implicit communication is used, whether explicit communication should/could be used and whether there is a requirement for identical Situational Awareness, or merely compatible Situational Awareness. We should point out that this critique is a theoretical exercise for the purposes of illustration, and, therefore, does not represent the views of the organization from which the data was sourced, or form the basis for any existing or expected recommendations. The intention in 
TABLE 5

Advantages and disadvantages of existing comms media

\begin{tabular}{|c|c|c|}
\hline Media & Advantages & Disadvantages \\
\hline $\begin{array}{l}\text { Mobile } \\
\text { Phone }\end{array}$ & $\begin{array}{l}\text { 1. use of stored phone book means } \\
\text { numbers can be dialed more quickly } \\
\text { and reliably } \\
\text { 2. portable and therefore can be used in a } \\
\text { variety of locations, ideally reducing } \\
\text { effects of background noise or working } \\
\text { in darkness } \\
\text { 3. could be hands free, so forms could be } \\
\text { completed simultaneously } \\
\text { 4. calls logged by mobile phone company } \\
\text { if accident occurs } \\
\text { 5. when being called the display may } \\
\text { indicate who is calling or the number } \\
\text { they are calling from, improving } \\
\text { identification of who is being spoken to } \\
\text { 6. modern phones have some degree of } \\
\text { scheduling facility including call } \\
\text { waiting, messenging etc. }\end{array}$ & $\begin{array}{l}\text { 1. stored phone book may contain } \\
\text { incorrect numbers } \\
\text { 2. mobile phone reception may } \\
\text { lead to poor signal or loss of } \\
\text { signal and therefore failure of } \\
\text { communication } \\
\text { 3. if not communicating with signal } \\
\text { box then communication not } \\
\text { recorded } \\
\text { 4. only one call can be dealt with at } \\
\text { a time, sequentially. }\end{array}$ \\
\hline $\begin{array}{l}\text { Signal Post } \\
\text { Telephone }\end{array}$ & $\begin{array}{l}\text { 1. sound stable } \\
\text { 2. increased likelihood of talking to correct } \\
\text { signaler }\end{array}$ & $\begin{array}{l}\text { 1. not hands-free but hands may } \\
\text { be required to complete } \\
\text { paperwork } \\
\text { 2. affected by environmental } \\
\text { conditions as outside } \\
\text { 3. close to track and therefore } \\
\text { increases risks of person using } \\
\text { phone being struck by a train } \\
\text { 4. if used in the dark there is } \\
\text { unlikely to be a light source } \\
\text { nearby } \\
\text { 5. background noise can be an } \\
\text { issue } \\
\text { 6. depending on signal spacing, } \\
\text { the SPT may still be some } \\
\text { distance away from actual } \\
\text { physical operations. }\end{array}$ \\
\hline $\begin{array}{l}\text { Signaler } \\
\text { Desk } \\
\text { Telephone }\end{array}$ & $\begin{array}{l}\text { 1. Sound stable } \\
\text { 2. communication recorded and kept for } \\
\text { future scrutiny }\end{array}$ & $\begin{array}{l}\text { 1. not hands free for signaler who } \\
\text { may write in log and operate } \\
\text { signaling equipment while on the } \\
\text { phone } \\
\text { 2. communications are } \\
\text { unscheduled, with possible } \\
\text { interference with concurrent } \\
\text { safety critical tasks. } \\
\text { 3. only one call at a time can be } \\
\text { dealt with, sequentially. }\end{array}$ \\
\hline
\end{tabular}


this case is to provide a creative and unrestrained review of communications media in a given scenario merely for the purposes of demonstration.

Phase 1-Prepare for the Possession (Knowledge Objects Represented in Fig. 5 Enclosed by $<>$ )

Part of preparing for the possession is the Signaler and PICOP agreeing that possession protection can be placed. If the PICOP and Signaler had linked situational displays relating to shared knowledge on <possession>, $<$ trains $>$ and <network $>$, then the PICOP could send a standard message that would be presented on the Signaler's display, which would inform the Signaler that the possession is requested. Both the Signaler and PICOP could review their displays to identify <train> movements affecting the request. This could enable the PICOP to send a request at a time consistent with <train> movements in the area, meaning less interference with the signaler's task and greater probability of the request being granted first time. Similarly, the display could incorporate <information> from the <weekly operating notice>, meaning that the signaler will be expecting a <call $>$ from the PICOP at a given <time> and that <train> movements may need to be adjusted in advance. Using such a display, the signaler can either accept or reject the request by carrying out a further action on the display. The accept or reject message would be sent back to the PICOP. The display could potentially improve Signaler and PICOP situational awareness of trains and worksites. It could also automate elements of form completion, for example time stamping.

The PICOP, ES, and both CPs prepare for detonator protection. Detonators are a protective measure. They are affixed to the track so that in the event of ontrack plant or trains passing all the other protective measures in advance of these, they will alert the driver via audible means that they must stop immediately. In coordinating this step, the communication of factual information, routes to locations, actual locations, and so on are not time dependent. The choice of medium should include written information, such that details are not forgotten, but otherwise communication resources are flexible.

The final stage in preparing for the possession is the Signaler and PICOP agreeing that possession protection can be placed. If the PICOP and Signaler had linked situational displays, including the possession worksites, possession 
limits, etc., then the PICOP could send a standard message that would be presented on the Signaler's display, which would inform the Signaler that the possession is requested. The Signaler could then review the display to identify that there were no train movements affecting the request and then either accept or reject the request by carrying out a further action on the display. The accept or reject message would be sent back to the PICOP. The display could potentially improve Signaler and PICOP situational awareness of trains and worksites. It could also automate elements of form completion (e.g. time stamping). We should note that if the information could be fully integrated into the Signaler display, then it might be possible for the Signaler to overlap with some or all of the PICOP's tasks in cases where this would enhance safety. Additionally, in certain circumstances (with appropriate technical solutions being discussed), it may be possible for the PICOP to be based in the same location as the Signaler. This possibility would allow for optimal communication and sharing of situational awareness between the two parties.

\section{Phase 2-Implement Possession Protection}

Phase 2 is the simple transfer of an expected instruction between the PICOP and the CP. This transfer could be communicated by an unambiguous alert to the $\mathrm{CP}$ from the $\overline{\mathrm{PICOP}}$, such as a standard text message or unique aural alert. If there were a number of Competent People to coordinate, then the message could be sent to all of them at the same time through multiple addressing.

The CP and the PICOP then have to confirm that possession protection has been placed. As before, this is the simple transfer of an expected instruction which could be communicated by an unambiguous alert to the PICOP from the $\mathrm{CP}$, such as a standard text message or unique aural alert. The same applies to the Signaler and PICOP when confirming that possession protection has been placed, and in granting the possession to the PICOP. This message would require specific confirmation from the Signaler, which would signify both that the communication had been received from the PICOP and that the possession had been granted. This could also be a text message or unique aural alert. 


\section{Phase 3-Set-Up the Worksite}

This is the simple transfer of an expected instruction between the PICOP and ES. This could be communicated by an unambiguous alert to the ES from the PICOP, such as a standard text message or unique aural alert. If there were a number of Engineering Supervisors to coordinate, then it could be sent to all of them at the same time through multiple addressing. If the PICOP had a live situational display of possession worksites, possession limits, etc., this could be used to select, generate, and send the message. The display could improve PICOP Situational Awareness of worksites and could automate elements of form completion (e.g. time stamping) as well.

The ES instructs the second CP to implement worksite marker boards. This is the simple transfer of an expected instruction. This could be communicated by an unambiguous alert to the CP from the ES, such as a standard text message or unique aural alert. If there were a number of Competent People to coordinate, then it could be sent to all of them at the same time through multiple addressing.

Confirmation that worksite marker boards have been placed then must be sought. This is the simple transfer of an expected instruction. This could also be communicated by an unambiguous alert to the ES from the second $\mathrm{CP}$, such as a standard text message or unique aural alert.

\section{Phases 4 and 5-Authorize Work to Start in Worksite (Begin Work)}

The PICOP and ES then have to confirm that worksite marker boards have been placed and authorize work to start in a worksite. This again is the simple transfer of an expected instruction. This could be communicated by an unambiguous alert to the ES from the PICOP, such as a standard text message or unique aural alert. This message would require specific confirmation from the PICOP which would signify both that the communication had been received from the ES and that work is authorized to start in the worksite.

\section{CONCLUSIONS}

The general points derived from this analysis of communications in railway-maintenance scenarios are the following: 
- Assessment is required of workload for visual and aural channels to determine whether verbal or visual communications should be preferred.

- Possibly, headsets may have to be used to minimize physical disturbance to other tasks.

- If automated systems are to be used, then it must be demonstrated that the reliability of data sources input into automated systems provide better reliability than verbal communications do, and that the opportunities for recovery are greater. The reliability of interfaces to select values, rather than using voice communication, would also need to be assessed.

- Individuals are required to attend to voice messages but can delay responses to alarms or text messages. The impact of this factor on timecritical tasks would have to be assessed if verbal communication was not to be used.

- The impact on the use of automated or non-verbal communications on team performance would have to be assessed, as would whether team performance is actually required.

- Finally, whether each message that is not sent verbally would require a confirmation of message receipt to be generated by the message receiver (and sent back to the message sender) would also have to be assessed.

The methodology achieves this level of critique by deriving a novel but powerful representation of required knowledge and its interrelation. In so doing, the distributed and dynamic nature of Situational Awareness (SA) can be viewed in a very real sense.

The first key point is that knowledge and SA can be held by human and non-human agents, such as documentation, trains, equipment etc. This knowledge is held to the extent that it enables artefacts to represent themselves in a number of different states.

Secondly, there are multiple views of SA of the same scene for different agents. The knowledge underpinning the Signaler and Person In Charge Of Possession's (PICOP) SA comprises quantitatively different things.

Third, the extent of overlap between the Signaler and PICOP's SA depends on the agents goals. The PICOP is aiming to secure the possession, while the Signaler is identifying the feasibility of carrying out the request. To that extent, certain items of knowledge will be shared and will have to be communicated, 
such as time, possession information, rail network information, etc.

Fourth, communication between agents is not necessarily explicit. A certain degree of informality, customs, and practice either serve as prompts for either agent to probe for more information or are taken as implicit feedback in itself.

Fifth, distributed and dynamic SA holds this form of loosely coupled system together. The relation between the Signaler, the PICOP, and the rail network is bound by their respective levels of knowledge on the movement of trains and the safety of proceeding with maintenance activities on the track.

Sixth, and finally, one agent may be able to compensate for degradation in the SA in another agent. These fundamental ideas on Distributed Situation Awareness form the basis for a new theory and approach.

A novel analysis of the application of information and communication technology in a real $\mathrm{C} 4 \mathrm{i}$ scenario has been demonstrated. This analysis takes place within a wider context of varied literature on distributed collaboration and collaboration engineering. Both areas are similarly concerned with the means to facilitate communication and collaboration in circumstances similar if not identical to those of $\mathrm{C} 4 \mathrm{i}$. What differentiates the current approach is that it is user-centered as opposed to being technology driven. In the most general terms, the literature on collaboration engineering frequently proceeds with a technology, be it videoconferencing (e.g. Nowak, et al., 2004), virtual community systems (e.g., Geib et al., 2004) or mobile communications infrastructures (Litio \& Zeitoun, 2004). The present knowledge-based approach does not constrain analysis or assessment to any particular form of technology. This approach provides cognitively based assessment criteria for technology to be assessed against or designed to. Specifically, the integration of several Human Factors techniques significantly enhances the level of critique available from the Communications Usage Diagram. In turn, this allows a coupling between theory and practical applications of technology in intelligent systems. The ultimate aim is to facilitate a match between technology and the knowledge requirements of $\mathrm{C} 4 \mathrm{i}$ scenarios.

\section{ACKNOWLEDGMENTS}

This work from the Human Factors Integration Defence Technology Centre (HFI DTC) was funded in part-by the Human Sciences Domain of the U.K. 
Ministry of Defence Scientific Research Programme.

The assistance of the Rail Safety and Standards Board is gratefully acknowledged, and the data presented here are used with their kind permission.

\section{REFERENCES}

Anderson, J.R. 1980. Cognitive psychology and its implications, San Francisco, California, USA, Freeman.

Annett, J. 2005. Hierarchical task analysis, in: Handbook of human factors and ergonomics methods, edited by Stanton, N., Hedge, A., Brookhuis, K., Salas, E. and Hendrick, H.W. London, UK, CRC, 33.1-33.7.

Annett, J. 2004. Hierarchical task analysis, in: Handbook of task analysis in human-computer interaction, edited by Diaper, D. and Stanton, N.A., Mahwah, New Jersey, USA, Lawrence Erlbaum Associates, 67-82.

Baber, C., Houghton, R.J., McMaster, R.M., Salmon, P., Stanton, N.A., Stewart, R.J. and Walker, G.H. 2004. Work package 1.1.1 field studies in the emergency services, HFI DTC Report, Yeovil, Somerset, UK, Aerosystems International.

Bell, H.H. and Lyon, D.R., 2000. Using observer ratings to assess situation awareness, in: Situation awareness analysis and measurement, edited by Endsley, M.R., Mahwah, New Jersey, USA, LEA, 129-146.

Collins, A.M., and Loftus, E.F. 1975. A spreading-activation theory of semantic processing, Psychological Review, 82, 407-428.

Endsley, M.R. 1995. Toward a theory of situation awareness in dynamic systems, Human Factors, 37, 32-64.

Gugerty, L.J. 1998. Evidence from a partial report task for forgetting in dynamic spatial memory, Human Factors, 40, 498-508.

Geib, M., Braun, C., Kolbe, L. and Brenner, W. 2004. Measuring the utilization of coloration technology for knowledge development and exchange in virtual communities, Proceedings of the $37^{\text {th }}$ Annual Hawaii International Conference on System Sciences HICSS, IEEE.

Harris, C.J. and White, I. 1987. Advances in command, control and communication systems, London, UK, Peregrinus.

Hollnagel, E. 1993. Human reliability analysis: context and control, London, UK, Academic Press.

Litiu, R., and Zeitoun, A. 2004. Infrastructure support for mobile collaboration, Proceedings of the $37^{\text {th }}$ Annual Hawaii International Conference on System Sciences HICSS, IEEE.

Kieras, D.E. 2004. GOMS models and task analysis, in: Handbook of task analysis in human-computer interaction, edited by Diaper, D and Stanton, N.A., Mahwah, New Jersey, USA, Lawrence Erlbaum Associates, 83-1 16. 
Klein, G. and Armstrong, A.A. 2005. Critical decision method, in: Handbook of human factors and ergonomics methods, edited by Stanton, N., Hedge, A., Brookhuis, K., Salas, E. and Hendrick, H.W., London, UK, CRC, 35.1-35.8.

Klein, G.A., Calderwood, R. and MacGregor, D. 1989. Critical decision method for eliciting knowledge, IEEE Transactions on Systems, Man, and Cybernetics, 19, 462-472.

Moray, N. 2004. Ou' sont les neiges d' antan? Proceedings of the HPSAAII. Mahwah, New Jersey, USA, Lawrence Erlbaum Associates.

Nowak, K.L., Watt, J., Walther, J.B., Pascal, C., Hill, S., and Lynch, M. 2004. Contrasting time mode and sensory modality in the performance of computer mediated groups using asynchronous videoconferencing, Proceedings of the $37^{\text {th }}$ Annual Hawaii International Conference on System Sciences HICSS, IEEE.

O'Hare, D., Wiggins, M., Williams, A. and Wong, W. 2000. Cognitive task analysis for decision centred design and training, in: Task analysis, edited by Annett, J. and Stanton, N.A., London, UK, Taylor and Francis, 170-190.

Ogden, G.C. 1987. Concept, knowledge and thought, Annual Review of Psychology, 38, 203-227.

Quillian, R. 1969. The teachable language comprehender: a simulation program and theory of language, Communications of the ACM, 12459124476.

Rail Safety and Standards Board RSSB. 2003. Master rule book, Newark, New Jersey, USA, Willsons.

Rogers, Y. 1997. A brief introduction to distributed cognition, Interact Lab, University of Sussex, Brighton, UK.

Rolt, L.T.C. 1955. Red for danger: the classic history British railway disasters, Gloucestershire, UK, Sutton Publishing.

Salas, E., Prince, C. and Baker D.P. 1995. Situation awareness in team performance-implications for measurement and training, Human Factors, 37, 123-136

Smith, K., and Hancock, P.A. 1995. Situation awareness is adaptive, externally directed consciousness, Human Factors, 37, 137-148.

Stanton, N.A., Baber, C. and Young, M.S. 2005. Observation, in: Handbook of human factors and ergonomics methods, edited by Stanton, N., Hedge, A., Brookhuis, K., Salas, E. and Hendrick, H.W., London, UK, CRC, 28.1-28.7.

Stanton, N.A., Stewart, R., Harris, D., Houghton, R.J., Baber, C., McMaster, R., Salmon, P., Hoyle, G., Walker, G., Young, M.S., Linsell, M. and Dymott, R. Submitted. Distributed situational awareness in dynamic systems: theoretical development and application of an ergonomics methodology, Ergonomics. 
Sukthankar, R. 1997. Situation awareness for tactical driving, unpublished doctoral dissertation, Carnegie Mellon University, Pittsburgh, Pennsylvania, USA.

Walker, G.H., Stanton, N.A., Wells, L. and Gibson, H. 2005. Report on results of WP1.1 methodology for national air traffic services data. HFI DTC Report. Yeovil, Somerset, UK, Aerosystems International.

Watts, L.A. and Monk, A.F. 2000. Reasoning about tasks, activities and technology to support collaboration, in: Task analysis, Annett, J. and Stanton, N., UK, Taylor and Francis, 55-78.

Young, S.J. 1982. Real time languages: design and development, Chichester, UK, Ellis Horwood. 
